\title{
DOES ELLIPSIS REPAIR HEAD MOVEMENT CONSTRAINT VIOLATIONS?
}

Geosel Mendes*

\begin{abstract}
Using English data, I show that Head Movement Constraint violations cannot be repaired by deletion and compare this result with cases of both salvation and non-salvation by ellipsis from previous literature. I then consider two possible sources for this lack of repair. The first is to take the Head Movement Constraint as a derivational constraint, and the second is to assimilate it into the Empty Category Principle (Chomsky, 1986).

Keywords: Head Movement Constraint; Repair by Ellipsis; Derivational Constraints; Representational Constraints
\end{abstract}




\section{Introduction}

Since Ross (1969), ellipsis has been used to probe into the nature of locality restrictions on movement (Perlmutter, 1971; Chomsky, 1972; Chung et al., 1995; Merchant, 1999; Lasnik, 2001; Nakao, 2009; Bošković, 2011; among many others). The existence of repair effects implies that the relevant constraints are at least partly representational. Let us consider an example of Ross's Complex NP Constraint (adapted from Lasnik, 2001):

1) a. ${ }^{*}$ They didn’t hire anyone who speaks a certain Romance language. Guess which Romance language they didn't hire [anyone $\left[_{R C}\right.$ who speaks $\left.t\right]$ ]!

b. They didn't hire anyone who speaks a certain Romance language. Guess which (Romance language) they didn't hire anyone $f_{R C}$ who speaks t]!

In (1a), we have $w$ h-movement across a complex NP and thus an island effect arises. In the sluicing example in (1b) we also have the problematic movement, but the relevant portion of the structure is removed and acceptability improves.

The main idea in the literature on repair is that movement that crosses an island causes a local representation problem, marked below with a *-feature on the island boundary (Chomsky, 1972; Lasnik, 2001; Merchant, 2008; Bošković, 2011). Ellipsis removes the portion of the structure that contains the ${ }^{\star}$-feature and thus the problem goes away:

2) a. Mary wants to find any student I gave a certain book to, but I don't know which book Mary wants to find ${ }^{*}$ [any student $\left[{ }_{\mathrm{RC}}\right.$ I gave $t_{\text {which_book }}$ to]] b. Mary wants to find any student I gave a certain book to, but I don't know which book Mary wants to find * [any student $\mathrm{f}_{\mathrm{RC}}$ I gave $t_{\text {which_book }}$ to $]$ ] (PF deletion)

One type oflocality constraint that, to my knowledge, has notbeen investigated in the literature on repair is the Head Movement Constraint (henceforth HMC; Travis, 1984), which requires head movement to be maximally local and upwards. The HMC, for instance, blocks structures like (3):

3) ${ }^{*}\left[{ }_{\mathrm{XP}} \mathrm{X}+\mathrm{W}\left[{ }_{\mathrm{ZP}} \mathrm{Z}\left[{ }_{\mathrm{WP}} t_{\mathrm{w}}\right]\right]\right]$

Here the head $\mathrm{W}$ adjoins to the head $\mathrm{X}$ jumping over $\mathrm{Z}$. This results in a violation of the HMC.

In this paper, I will show that ellipsis does not repair HMC violations like the one in (3) and explore some reasons why.

In section 2, I introduce some evidence that ellipsis involves unpronounced syntactic structure. In section 3, I present some previous results from the literature 
on repair. In section 4, I show that HMC violations of the type in (3) do not seem to be repaired by deletion. In section 5 , I speculate some reasons for such absence of repair. Finally, in section 6, I conclude.

\section{Evidence for unpronounced structure in the ellipsis site}

In this section, I review some evidence that ellipsis sites involve unpronounced syntactic structure, which I will implement in terms of PF-deletion. This is not an exhaustive list of arguments, but I believe that the evidence reviewed here suffices to motivate the idea. ${ }^{1}$

Bound pronouns must be c-commanded by their binder at some point of the derivation (Lasnik, 1976). Now, consider the following example from van Craenenbroeck and Merchant (2013):

4) A: What does every professor ${ }_{1}$ wants to talk about?

B: One of his ${ }_{1}$ books every professor ${ }_{+}$wants to talk about $t$.

The requirement is satisfied if the fragment answer in $B$ includes unpronounced syntax, i.e. before movement and $\mathrm{PF}$-deletion. A similar point can be made with anaphors, which are required to be A-bound in their local domain (Lasnik, 1976, Chomsky, 1981, and subsequent work).

5) John saw some pictures, but I don't know how many (pictures) of himself fohnt

Another argument, given by Ross (1969), is based on agreement. If agreement requires a c-command relation between the agreement controller and the element exhibiting agreement morphology, examples like the following imply that the material inside the ellipsis site, containing the agreement controller, is syntactically active before PF-deletion:

6) Some people think that there aren't such rules, but there $\left\{\right.$ are $/{ }^{*}$ is $\}$ streh rules.

Additionally, ellipsis also seems to require some degree of isomorphism with the antecedent, which again suggests the presence of unpronounced syntactic structure. For instance, Chung (2006) observes that ellipsis sites cannot include new words that are not in the antecedent. Consider the following examples:

7) John is jealous of someone, but I don't know who John is jealous of $t$.

8) a. ${ }^{\star} J o h n$ is jealous, but I don’t know who fohn is jealous of $t$.

b. John is jealous, but I don't know of who fohn is jealous t. 
The preposition of in these examples is just a meaningless case marker. If ellipsis requires some degree of syntactic identity, the pattern in (7) and (8) is easily explained. In (7) and (8b), all words in the ellipsis site are included in the antecedent. In (8a), on the other hand, the ellipsis site includes an extra word of, not present in the antecedent and therefore deletion is impossible as there is lack of identity between what we are trying to elide and its potential antecedent.

The final argument I will present here is based on Mendes and Nevins (2020), who point out that the defectiveness of some modal verbs in English is carried over to ellipsis sites. Specifically, modal verbs like must in English lack non-finite forms (e.g., ${ }^{\star}$ don't must, ${ }^{\star}$ musted, ${ }^{\star}$ is musting, ${ }^{\star}$ have musted, ${ }^{*}$ will must, ...), in contrast with modals like has (to) (e.g., I don't have to go, I will have to go, etc ...). Consider then the following contrast:

9) ${ }^{\star}$ John must leave, but I don't must leave.

10) John has to leave, but I don't have to leave.

If hidden syntactic structure were not required in VP ellipsis here, it is unclear how to block the example in (9). If there is hidden syntactic structure, (9) is ruled out because the relevant syntactic structure in the ellipsis site cannot be built to begin with, given the defectiveness of must in English. ${ }^{2}$

Let us consider now some constraints on movement and how they behave under ellipsis.

\section{Representational constraints at PF and LF and derivational constraints}

Ross gave several examples of potential repair effects (some examples are slightly modified):

11) Complex NP Constraint, noun complement

a. ${ }^{\star}$ I believe the claim that he bit a certain student, but they don't know which student I believe the claim that he bit $t$.

b. I believe the claim that he bit a certain student, but they don't know which student.

12) Complex NP Constraint, relative clause

a. ${ }^{*}$ She kissed a man who bit one of my friends, but I don't know which of my friends she kissed a man who bit $t$.

b. She kissed a man who bit one of my friends, but I don't know which of my friends. 
13) Coordinate Structure Constraint

a. ${ }^{\star}$ Irv and someone were dancing together, but I don’t know who Irv and $t$ were dancing together.

b. Irv and someone were dancing together, but I don't know who.

Here are other examples that have appeared in the literature:

15) Comp-trace effect (adapted from Chung et al., 1995)

a. ${ }^{*}$ Sally asked if somebody was going to fail Syntax One, but I can't remember who Sally asked if $t$ was going to fail Syntax One.

b. Sally asked if somebody was going to fail Syntax One, but I can't remember who.

16) Left branch extraction (adapted from Merchant, 1999)

a. ${ }^{\star}$ He wants a detailed list, but I don't know how detailed he wants a $t$ list.

b. He wants a detailed list, but I don’t know how detailed.

17) Adjunct island (adapted from Merchant, 2008)

a. ${ }^{\star}$ Ben will be mad if Abby talks to one of the teachers, but she couldn't remember which (one of the teachers) Ben will be mad [if Abby talks $t$ ].

b. Ben will be mad if Abby talks to one of the teachers, but she couldn't remember which (one of the teachers).

19) Subject island (adapted from Merchant, 1999)

a. ${ }^{*} \mathrm{~A}$ biography of one of the Marx brothers is going to be published this year - guess which (of the Marx brothers) [A biography of $t$ ] is going to be published this year!

b. A biography of one of the Marx brothers is going to be published this year - guess which (of the Marx brothers)!

20) Wh-island

(adapted form Merchant, 2008)

a. ${ }^{\star}$ Sandy was trying to work out which student would solve a certain problem, but I don't know which problem she was trying to work out which student would solve $t$.

b. Sandy was trying to work out which student would solve a certain problem, but I don't know which problem.

Each of these constraints, as well as the corresponding repair examples, deserve careful examination. I refer the reader to Merchant (1999), Lasnik (2001), Merchant (2008), Bošković (2011), Rottman and Yoshida (2013), Barros et al. (2014).

Repair effects imply that the grammar can build the relevant deviant structures and that unacceptability arises as an output condition on the PF side. 
That is, movement is possible, but the structure is filtered out at PF if deletion does not apply. As done in the introduction, I will proceed here by marking the locality violations with $\mathrm{a}^{*}$-feature placed on the relevant portion of the structure.

21) Complex NP Constraint, noun complement

I believe the claim that he bit a certain student, but they don't know which student fbelieve * the claim that he bit $t]$.

22) Complex NP Constraint, relative clause

She kissed a man who bit one of my friends, but I don't know which of my friends She kissed * a man who bit t].

23) Coordinate Structure Constraint

Irv and someone were dancing together, but I don't know who ${ }^{*}$ [rv and $\left.t\right]$ were daneing together.

24) Comp-trace effect

Sally asked if somebody was going to fail Syntax One, but I can't remember who Sally asked ${ }^{*}$ if $t$ was going to fail Syntax One

25) Left branch extraction

He wants a detailed list, but I don't know how detailed he wants a * $[t$ list $]$.

26) Adjunct island

Ben will be mad if Abby talks to one of the teachers, but she couldn't remember which Ben will be mad * [if Abby talks t].

27) Subject island

A biography of one of the Marx brothers is going to be published this year - guess which (of the Marx brothers) $*$ [A biography of $t]$ is going to be published this year!

28) Wh-island

Sandy was trying to work out which student would solve a certain problem, but I don't know which problem she was trying to work out * which student would solve t.

Let us turn now to cases where repair fails.

Merchant (1999) argues that PF-representational constraints can be repaired by deletion whereas derivational constraints cannot. If a given constraint is derivational, we should not see repair effects because the grammar would not be able to build the structure to begin with. For example, Merchant observed that Superiority effects cannot be repaired by deletion. To show this, he used data 
from Bulgarian, a language which allows multiple wh-movement (see Rudin, 1988 and Richards, 1997 for further discussion):

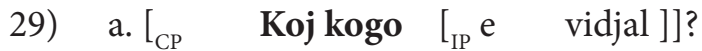

who whom AUX seen

'Who saw who?'

b. ${ }^{\star}$ Kogo koj e vidjal?

Superiority violations cannot be repaired by deletion as shown in the following examples:

30) a. Njakoj e vidjal njakogo, no ne znarn $\left[{ }_{\mathrm{CP}} \operatorname{koj} \operatorname{kogo} \mathrm{f}_{\mathrm{FP}}\right.$ vidjalt]. someone AUX seen someone but not I. know who whom AUX seen 'Someone saw someone, but I don't know who saw who.'

b. ${ }^{\star}$ Njakoj e vidjal njakogo, no ne znarn kogo koj.

Finally, Lasnik (2005) and Nakao (2009) also observed that ellipsis does not seem to rescue ECP violations (Chomsky, 1981; Lasnik \& Saito, 1984; Lasnik \& Saito, 1992), which require traces to be properly governed. Basically, a trace is properly governed if it is governed by a lexical head or by its antecedent. The examples Lasnik and Nakao discuss are given below: ${ }^{3}$

31) a. John wants to hire [someone who fixes cars with something], but I don't know what. fohn wants to hire [someone who fixes cars with $t$ ].

b. ${ }^{\star}$ John wants to hire [someone who fixes cars for a certain reason], but I don't know (exactly) why fohn wants to hire [someone who fixes cars $t$ ].

c. ${ }^{*}$ John wants to hire [someone who fixes cars in a certain way], but I don't (exactly) know how fohn wants to hire [someone who fixes cars $t$ ].

32) a. John will be mad [if Mary dances with a certain guy], but I don't know who John will be mad [if Mary dances with t].

b. ${ }^{\star} J o h n$ will be mad [if Mary dances for a certain reason], but I don't know why fohn will be mad [if Mary danees t].

c. ${ }^{*}$ John will be mad [if Mary dances in a certain way], but I don't know how fohn will be mad [if Mary dances t].

In the examples in (a), the trace within the island is lexically governed by the preposition with, a lexical head. On the other hand, in the examples in (b) and (c) in both (31) and (32), the traces of the adjuncts are not properly governed. They are not governed by a lexical head, nor by their antecedents since the adjunct structure is a barrier. The lack of repair is predicted if the ECP is an LF representational constraint, whereas ellipsis is PF-deletion. ${ }^{4}$

With these observations in mind, I now turn to HMC violations. 


\section{HMC violations are not repaired by ellipsis}

Travis's (1984) Head Movement Constraint (HMC) requires head movement (HM) to be upwards and maximally.

33) ${ }^{*}\left[{ }_{\mathrm{XP}} \mathrm{X}+\mathrm{W}\left[{ }_{\mathrm{ZP}} \mathrm{Z}\left[{ }_{\mathrm{WP}} t_{\mathrm{W}}\right]\right]\right]$

It is my understanding that $\mathrm{HMC}$ violations have not been tested for repair by deletion. Finding examples of HMC violations that don not have other confounds in English is not an easy task. Most of the examples of HMC violations given in the literature have also other problems as well.

Examples (34) and (35), below, are two candidates of HMC violations, where heads crossed by HM are marked in italics. For the sake of exposition, assume that auxiliaries and copula be project a VP, and their tensed forms are the result of V-to-T movement (for a different approach, see Lasnik, 1995, among others):

34) ${ }^{*}$ Be John can tbe happy?

35) ${ }^{\star} J o h n$ is can tbe happy.

In (34), be moves to C crossing can; in (35), be moves to $\mathrm{T}$ crossing can. Ellipsis does not seem to make the examples any better:

36) A: John can be happy.

B: ${ }^{\star B e}$ he can $\{\forall p$ tean $[\forall p$ tbe happy $]$ ? (cf. Can he?)

37) ${ }^{*}$ Mary can be happy, and John is fvp [vptbe happy] too. (cf. ... John can too.)

All the examples above have confounds, though (Lasnik, 2000, sections 3.4.4/3.4.6). If question formation involves $\mathrm{T}$-to-C, bare $b e$ is not eligible to raise to $\mathrm{C}$ in $(34) /(36 \mathrm{~B})$. Also, can, like some other English modals, lacks untensed forms $\left({ }^{*}\right.$ must can,${ }^{*}$ will can,${ }^{*}$ is can $($ ing $),{ }^{*}$ doesn't can, ...), so (35)/(37) might be independently bad because be 'steals' $\mathrm{T}$ from can. Finally, in (36B), a head crossed by HM stays outside the ellipsis site rendering the example irrelevant to the discussion since the HMC violations are not properly included in the ellipsis site.

Consider now the following examples, which control for such interfering factors:

38) ${ }^{\star}$ John is seem to $t_{\mathrm{be}}$ happy.

(cf. John seems to be happy)

39) ${ }^{\star}$ Peter seems to be happy, but John isn’t [vp-seem to t te happy].

(cf. Peter seems to be happy, but John doesn’t f $\forall$-seem to be happy] too) 
40) ${ }^{\star}$ Ann has appear to $t_{\text {have }}$ been sick.

(cf. Ann appears to have been sick)

41) ${ }^{\star}$ Mary appears to have been sick, and Anna has $\mathrm{f}_{\mathrm{VP}}$ appear to thave ${ }_{\text {har }}$ been siekf too.

(cf. Mary appears to have been sick, and Anna does $\mathrm{f}_{\mathrm{VP}}$ appear to have been sickf too)

The HMC is violated in (38-39) as the heads seem and to are crossed by HM. Likewise, the HMC is also violated in (40-41), where appears and to are crossed by have in its way up to T. We find no amelioration under ellipsis in (39) and (41), though, which indeed suggests that a HMC violation cannot be repaired by deletion

We should also check for other potential interfering factors here.

First, notice that HM from a 'reduced' extended projection to another extended projection is what we find in noun incorporation:

42) Juan ngilla-waka-fi-y $\quad\left[_{\mathrm{NP}} t_{\text {waka }}\right.$ Pedro $]$.

Juan buy-cow-30-ind.3s.s $\quad\left[_{\mathrm{NP}} t_{\text {cow }}\right.$ Pedro]

'Juan bought Pedro's cow.' ～(adapted from Baker et al., 2005)

So, the fact that be moves to a distinct extended projection should not be a problem in (38-41). ${ }^{5}$ Second, notice that be can move to T outside a deleted VP whose antecedent clause does not have to be in a parallel position. (43a) shows that English does not have productive AP-ellipsis, which implies that (43b) has a derivation along the lines just described.

43) a. ${ }^{*}$ Peter isn’t being noisy, but John is [VP being fAP noisy]]. (cf. ... John is.)

b. Peter is [VP being [AP noisy]], he always is [¥P tbe [AP noisy]].

The problem with (40), therefore, is unlikely to be a lack of parallelism.

Finally, we should also consider the possibility of seem being introduced by $\mathrm{v}_{\mathrm{i}}$ (ntransitive) and issues that might arise from it. ${ }^{6}$ Regardless of the presence of $\mathrm{v}_{\mathrm{i}}$, it is unlikely that a locality issue other than the HMC is at play in (38-41). $v_{i}$ 's that introduce verbs like seem, which do not require an external argument, are weak phase heads (Chomsky, 2001). Furthermore, T and VP internal material can arguably be syntactically related as shown in the agreement established between Peir 'they.NOM', inside the VP headed by leiðst 'bored.at', and the auxiliary höf $f u$ 'had.3PL' (44), and there is no other potential phasal domain between T and the base position of be in (38-39) and $\mathrm{T}$ and the base position of have in (40-41).

44) Henni höfðu leiðst Peir.

her.dat had.3PL bored.at they.NOM

'She had found them boring. （Icelandic; Sigurðsson, 2002, p. 692) 
Consider now the following possible parses for (39) and (40) assuming seem and appear are introduced by $\mathrm{v}_{\mathrm{i}}$ :

45) a. ${ }^{\star P e t e r ~ s e e m s ~ t o ~ b e ~ h a p p y, ~ b u t ~ J o h n ~ i s n ’ t ~[v P ~ V i ~ f v p-s e e m ~ t o ~ t b e ~ h a p p y]] . ~}$

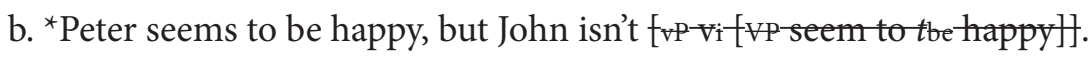

46) a. ${ }^{*}$ Mary appears to have been sick, and Anna has [vP Vi $f_{\mathrm{VP}}$ apper to $t_{\text {have }}$ been siek\}t too.

b. ${ }^{*}$ Mary appears to have been sick, and Anna has $\mathrm{f}_{\mathrm{PP}} \mathrm{Vi}_{\mathrm{H}} \mathrm{f}_{\mathrm{IP}}$ been sickf too.

In (45a) and (46a), one of the heads crossed by HM stays outside the ellipsis site, which would make the examples irrelevant for our discussion. However, it seems that v's must stay inside the ellipsis site to prevent overgeneration of verb phrase ellipsis in cases where the $\mathrm{v}$ in the ellipsis site and the $\mathrm{v}$ in the antecedent do not match, i.e., $\mathrm{v}_{\mathrm{i}}\left(\right.$ ntransitive) $\neq \mathrm{v}_{\mathrm{t}}$ (ransitive) (Merchant, 2013, and references therein):

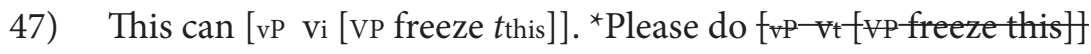

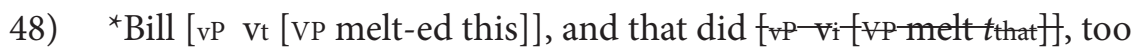

I therefore take (38-41) to be bona fide examples of HMC violations and (39) and (41) to show that HMC violations cannot be repaired by deletion.

\section{What type of constraint is the HMC?}

As mentioned before, Merchant (1999) argued that derivational constraints cannot be repaired by deletion, while representational constraints can. In the first case, the grammar would not be able to generate the relevant structures. In the latter, the grammar must be able to generate the relevant structures and, if the deviance is assigned to a representational PF-constraint, ellipsis should be able to fix the problem. If Merchant's rationale is right, HMC could be taken as a derivational constraint alongside Superiority.

HMC, superiority, and wh-islands, which we considered here, are often seen as instances of a more general Minimality condition (Rizzi, 1990; Chomsky, 1995). The idea is that violations arise when there is an intervening element, which, potentially, could have been the target of movement, between the base position of the moved element and its final position (e.g., $\alpha \ldots \beta_{\text {intervenor }} \ldots t_{\alpha}$ ).

As we saw, however, HMC, superiority, and wh-islands do not have a uniform behavior in terms of repair. While HMC and Superiority effects cannot be repaired by deletion, $w h$-islands can (relevant examples repeated below): 
49) ${ }^{\star}$ Peter seems to be happy, but John isn’t $\left[¥ p\right.$ seem to $t_{\text {be }}$ happy]. (cf. ... John doesn't.)

50) a. Njakoj e vidjal njakogo, no ne znarn $\left[_{C P}\right.$ koj kogo $t_{\mathrm{IP}}$ vidjalf]. someone AUX seen someone but not I.know who whom AUX seen 'Someone saw someone, but I don't know who saw who.'

b. ${ }^{\star N j a k o j ~ e ~ v i d j a l ~ n j a k o g o, ~ n o ~ n e ~ z n a r n ~ k o g o ~ k o j . ~}$

51) Wh-island

Sandy was trying to work out which student would solve a certain problem, but I don't know which problem she was trying to work out * which student would solvet.

Boeckx and Lasnik (2006), considering the contrast between $w h$-islands and Superiority, suggest that the crucial difference relies on the type of intervention. Wh-islands would be a case of defective intervention since the higher whmovement, the intervenor, cannot itself move to the matrix CP as shown in (52b):

52) Wh-Islands

a. ${ }^{\star}$ Which problem 2 was she trying to work out which student would solve $t_{2}$

b. ${ }^{\star}$ Which student ${ }_{1}$ was she trying to work out $t_{1}$ would solve which problem?

The situation is different with Superiority:

53) Superiority

(adapted from Boeckx \& Lasnik, 2006)

a. ${ }^{\star}$ Sue asked me what ${ }_{2}$ who bought $t_{2}$ ?

b. Sue asked me who $t_{1}$ bought what?

The examples of HMC violation that we found, however, resemble defective intervention as the intervening heads are not competing for T. Consider:

54) a. ${ }^{\star} J o h n$ isn't [vp seem to $t_{\text {be }}$ happy].

(HMC violation)

b. ${ }^{\star} J o h n$ seemn’t ${ }_{\mathrm{VP}} t_{\text {seem }}$ to be happy].

(seem to T)

c. ${ }^{\star}$ John to $+\mathrm{s}\left[{ }_{\mathrm{VP}}\right.$ seem $t_{\mathrm{to}}$ be happy].

(to to T, HMC violation)

d. John doesn't ${ }_{\mathrm{VP}}$ seem to be happy].

(do-support)

55) a. ${ }^{\star}$ Anna hasn’t [vp appear to $t_{\text {have }}$ been sick].

(HMC violation)

b. ${ }^{*}$ Anna seemn’t $\left[{ }_{\mathrm{VP}} t_{\text {seem }}\right.$ to have been sick].

(seem to T)

c. ${ }^{\star}$ Anna to $+\mathrm{s}\left[{ }_{\mathrm{VP}}\right.$ appears $t_{\mathrm{to}}$ be sick].

(to to T, HMC violation)

d. Anna doesn't [ ${ }_{\mathrm{VP}}$ appear to have been sick].

(do-support) 
These results complicate a unified view of HMC and Superiority.

Finally, we also saw that ECP effects cannot be repaired by ellipsis (data repeated below). According to Lasnik and Nakao, this is so because ECP is a representational LF constraint, whereas ellipsis is PF-deletion.

56) a. John wants to hire [someone who fixes cars with something], but I don't know what. John wants to hire [someone who fixes ears with $t$ ]. b. ${ }^{*}$ John wants to hire [someone who fixes cars for a certain reason], but I don't know (exactly) why fohn wants to hire [someone who fixes cars $t$ ].

c. ${ }^{\star} J o h n$ wants to hire [someone who fixes cars in a certain way], but I don't (exactly) know how fohn wants to hire [someone who fixes cars $t$ ].

57) a. John will be mad [if Mary dances with a certain guy], but I don't know who John will be mad [if Mary dances with t].

b. ${ }^{\star}$ John will be mad [if Mary dances for a certain reason], but I don't know why fohn will be mad [if Mary dances t]. c. ${ }^{*}$ John will be mad [if Mary dances in a certain way], but I don't know how fohn will be mad [if Mary dances t].

Interestingly, Chomsky (1986) tried to reduce the HMC to the ECP. Under the assumption that a head cannot appear as a complement of a lexical head, to satisfy the ECP, a trace of a head thus can only be antecedent-governed. ${ }^{7}$ In Chomsky's (1986) system, all maximal projections are blocking categories and thus potential barriers. Consider again our examples showing that HMC violations cannot be repaired by deletion:

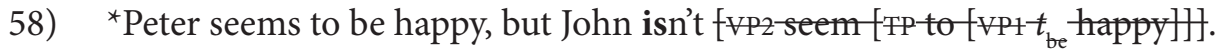

59) ${ }^{*}$ Mary appears to have been sick, and Anna has $\mathrm{f}_{\mathrm{VP} 2}$ apperr $\left[\mathrm{TP}\right.$ to $\left[\mathrm{VP} t_{\text {have }}\right.$ been sick\}] too.

In both examples, there are three barriers between the final position of the moving auxiliary verb and its, namely, VP1, TP (by inheritance), and VP2. As a result, $t_{\mathrm{be}}$ in (58) and $t_{\text {have }}$ in (59) are not properly governed. ${ }^{8}$ Again, if the ECP is an LF representational condition and ellipsis is PF-deletion, we do not expect repair effects.

\section{Conclusion}

I have shown that $\mathrm{HMC}$ violations cannot be repaired by deletion, apparently in contrast to some other locality violations. I speculated on two possible ways to accommodate this finding. The first was to say that the HMC is a derivational constraint building on Merchant (1999). In this case, there is no repair because the grammar cannot construct the relevant structure. I also showed that $w$ h-islands, 
HMC and Superiority do not exhibit a uniform behavior in terms of repair. The other possibility was to say that the HMC is reduced to the ECP as proposed by Chomsky (1986). The ECP, following Lasnik (2005) and Nakao (2009), would be an LF constraint while ellipsis is PF-deletion. The challenge now is to find a way to distinguish between these analytical options in an insightful way.

Notes

1. For a more complete discussion see van Craenenbroeck and Merchant (2013), which also go over most of the arguments presented here.

2. Mendes and Nevins (2020) also explore cases where lexical gaps can appear in the ellipsis site. In these cases, the source of defectiveness is morphophonological and thus repaired by deletion.

3. A reviewer points out that the ECP seems obsolete nowadays. In the minimalist era, notions like government, the heart of the ECP, became suspicious. While I share the idea that the ECP should be derived from more general grammatical notions, I will keep using it as a descriptive tool as many of its achievements have not found a satisfying minimalist account yet.

4. Bošković (2011) presents a more radical view on repair phenomenon. His view on the Superiority effect is different from the one we have endorsed here.

5. If we are not dealing with different projections in the end, then the potential objection I am trying to address does not arise, and the problem in these examples must be the intervening heads.

6. A reviewer raises the possibility that other heads in the extended projection of the verb seem and appear and below T might be present in our testing examples (39-41). We could, for instance, conceive the presence of Agr and Asp projections. I will leave further investigations on the presence of such heads in our testing examples and how they might interfere with the HMC there for future research.

7. Another assumption that needs to be made is that a head cannot adjoin to maximal projections.

8. For sake of comparison, consider an example like "How tall $\underline{\text { is }}$ John $\int_{\mathrm{TP}} \underline{\underline{t}}\left[_{\mathrm{VP}} \underline{t} t_{\text {how }}\right.$ tall ]]" with cyclic head movement. According to Chomsky, T $\theta$-marks the VP. Since T is not a lexical category, however, it cannot L-mark the VP to void its status as a barrier. Once $\mathrm{V}$ moves to $\mathrm{T}$, the situation is different. The resulting complex head $\mathrm{V}+\mathrm{T}$ has both properties necessary to L-mark the VP. V is a lexical head and $\mathrm{T} \theta$-marks the VP. The complex V+T, thus, L-marks the VP, allowing the trace of the copula within the $\mathrm{VP}$ to be antecedent-governed. T-to-C is possible because $\mathrm{T}$ is not an inherent barrier.

\section{References}

Baker, M. C., Aranovich, R., \& Golluscio, L. A. (2005). Two types of syntactic noun incorporation: Noun incorporation in Mapudungun and its typological implications. Language, 81(1), 138-176.

Barros, M., Elliott, P., \& Thoms, G. (2014). There is no island repair. Unpublished manuscript.

Boeckx, C., \& Lasnik, H. (2006). Intervention and repair. Linguistic Inquiry, 37(1), 150-155.

Bošković, Ž. (2011). Rescue by PF deletion, traces as (non)interveners, and the $I$ emphThat-Trace effect. Linguistic Inquiry, 42(1), 1-44.

Chomsky, N. (1972). Some empirical issues in the theory of transformational grammar. In P. S. Peters (Ed.), The goals of linguistic theory (pp. 63-130). PrenticeHall. 
Chomsky, N. (1981). Lectures on government and binding. Foris Publications.

Chomsky, N. (1986). Barriers. MIT Press.

Chomsky, N. (1995). The minimalist program. MIT Press.

Chomsky, N. (2001). Derivation by phase. In M. Kenstowicz (Ed.), Ken Hale: A life in linguistics (pp. 1-52). MIT Press.

Chung, S. (2006). Sluicing and the lexicon: The point of no return. In R. T. Cover \& Y. Kim (Eds.), Berkeley Linguistic Society 31 (pp. 73-91). UC, Berkeley.

Chung, S., Ladusaw, W., \& McCloskey, J. (1995). Sluicing and logical form. Natural Language Semantics, 3, 1-44.

van Craenenbroeck, J., \& Merchant, J. (2013). Ellipsis phenomena. In M. den Dikken (Ed.), The Cambridge handbook of generative syntax (pp. 701-745). Cambridge University Press.

Lasnik, H. (1976). Remarks on coreference. Linguistic Analysis, 2, 1-22.

Lasnik, H. (1995). Verbal morphology: Syntactic structures meets the minimalist program. In H. Campos \& P. Kempchinsky (Eds.), Evolution and revolution in linguistic theory (pp. 251-275). Georgetown University Press.

Lasnik, H. (2000). Syntactic structures revisited: Contemporary lectures on classic transformational theory. MIT Press.

Lasnik, H. (2001). When can you save a structure by destroying it? In M. Kim \& U. Strauss (Eds.), Proceedings of the North East linguistic society 31 (Vol. 2, pp. 301-320). GLSA.

Lasnik, H. (2005). What kind of constraint is the EPP? [Class handout]. Cambridge, MA: LSA Summer Institute, MIT.

Lasnik, H., \& Saito, M. (1984). On the nature of proper government. Linguistic Inquiry, 15, 235-290.

Lasnik, H., \& Saito, M. (1992). Move alpha. Cambridge, Massachusetts: MIT Press.

Mendes, G., \& Nevins, A. (2020). Salvation and non-salvation of defectiveness under ellipsis. Unpublished manuscript.

Merchant, J. (1999). The syntax of silence: Sluicing, islands, and identity in ellipsis [Doctoral dissertation]. University of California.

Merchant, J. (2008). Variable island repair under ellipsis. In K. Johnson (Ed.), Topics in ellipsis (pp. 132-153). Cambridge University Press.

Merchant, J. (2013). Voice and ellipsis. Linguistic Inquiry, 44(1), 77-108.

Nakao, C. (2009). Island repair and non-repair by PF strategies [Doctoral dissertation]. University of Maryland.

Perlmutter, D. (1971). Deep and surface structure constraints in syntax. Holt, Rinehart and Winston.

Richards, N. W. (1997). What moves where when in which language? [Doctoral dissertation]. Massachusetts Institute of Technology.

Rizzi, L. (1990). Relativized minimality. MIT Press.

Ross, J. R. (1969). Guess who? In R. I. Binnick, A. Davison, G. M. Green, \& J. L. Morgan (Eds.). 5th Regional Meeting of the Chicago Linguistic Society. (pp. 252286). Chicago linguistics society.

Rottman, I., \& Yoshida, M. (2013). Sluicing, idioms and island repair. Linguistic Inquiry, 44(4), 651-668. 
Rudin, C. (1988). On multiple questions and multiple wh-fronting. Natural Language and Linguistic Theory, 6, 445-501.

Sigurðsson, H. Á. (2002). To be an oblique subject: Russian vs. Icelandic. Natural Language and Linguistic Theory, 20(4), 691-724.

Travis, L. (1984). Parameters and effects of word order variation [Doctoral dissertation]. Massachusetts Institute of Technology.

Recebido em: 30/04/2020

Aceito em: 23/07/2020 
